This paper is published in Current Psychology with the following reference:

Michinov, E., \& Michinov, N. (2021). Stay at home! When personality profiles influence mental health and creativity during the COVID-19 lockdown. Current Psychology. https://doi.org/10.1007/s12144-021-01885-3

\title{
Stay at Home! When Personality Profiles Influence Mental Health and Creativity during the COVID-19 Lockdown
}

\author{
Estelle Michinov*1 and Nicolas Michinov ${ }^{1}$
}

${ }^{1}$ Laboratoire de Psychologie, Cognition, Comportement, Communication (LP3C),

Department of Psychology, Univ Rennes, Rennes, France

\section{Author Note}

Estelle Michinov (iD https://orcid.org/0000-0001-5872-2450

Nicolas Michinov (iD https://orcid.org/0000-0002-6065-8061

We have no funding for this research. Special thanks to Amine Chakli, Juliette Le Gall, Jule Aumeunier, and Dorian Lemée for their help in collecting or coding data for this research. The two authors contributed equally to this work.

Data and supplemental materials are available on our OSF project page:

\section{https://osf.io/taqbz/}

We have no known conflict of interest to disclose.

Corresponding concerning this article should be addressed to Estelle Michinov, Université Rennes 2, Département de Psychologie, LP3C, Place du Recteur Henri le Moal, 35043 Rennes Cedex, France. Email: estelle.michinov@univ-rennes2.fr 


\begin{abstract}
With the COVID-19 outbreak, the population was suddenly forced to "stay at home". Although research suggests that social isolation affects health and wellbeing, reactions may vary depending on individuals. The current study assessed the relationships between personality variables (preference for solitude and Big Five personality), mental health (anxiety, stress, loneliness), and creativity, and tried to determine whether the identified personality profiles affect individuals' mental health and creativity. French respondents $(N=$ 430) filled in an online questionnaire during the first lockdown in Spring 2020. The results showed that the preference for solitude and personality variables of the Big Five predicted individuals' mental health and creativity. Moreover, a cluster analysis revealed three profiles of individuals: “Affiliation”, "Emotionally Stable Lonely” and "Emotionally Unstable Lonely". Results showed that individuals with "Affiliation" and "Emotionally Unstable Lonely" profiles expressed higher stress and anxiety, and the latter performed better on a divergent creative thinking task. By contrast, those with an "Emotionally Stable Lonely" profile expressed a lower level of loneliness, and performed better on a creative insight task. These findings reveal the importance of personality profiles in psychological reactions during lockdowns. With this knowledge, health professionals could develop appropriate interventions to accompany high-risk individuals in situations of social isolation.
\end{abstract}

Keywords: COVID-19, creativity, mental health, personality profiles, preference for solitude, social isolation 


\section{Stay at Home! When Personality Profiles Influence Mental Health and Creativity during the COVID-19 Lockdown}

The coronavirus disease 2019 (COVID-19) outbreak has led certain governments to restrict the movements of their populations, with lockdowns and "stay at home" orders to reduce pressure on healthcare systems. The lockdowns forced people to limit social contact and activities, and restricted travelling and outdoor activities. In many European countries, including France, the first strict lockdown lasted for 55 days from $17^{\text {th }}$ March 2020 to $11^{\text {th }}$ May 2020. It has been suggested that such quarantine measures, including self-isolation and social distancing, may affect people's physical and mental health (Brooks et al., 2020; Pietrabissa \& Simpson, 2020; Roychowdhury, 2020; Sibley et al., 2020; Taylor et al., 2008; World Health Organization, 2020). As part of prevention programs, recent studies have examined the role of demographics and differences between individuals to determine the psychological response of people facing the COVID-19 outbreak (Bacon \& Corr, 2020; Moccia et al., 2020). As individuals may tolerate social isolation differently, we aimed to determine whether individual differences in tolerance to social isolation would affect mental health and creativity during a forced long period of lockdown.

\section{The negative effects of social isolation}

Different terms have been used to reflect the preference for affiliation, such as “belongingness” (Baumeister \& Leary, 1995), “relatedness” (Deci \& Ryan, 1991), “connectedness" (Markus \& Kitayama, 1991) or "we-ness" (Jetten et al., 2020). It has been observed that individuals spend about $80 \%$ of their time in the company of others (Cacioppo 
et al., 2009), and that most people prefer affiliation when threatened or distressed (Williams et al., 2018), or building social relationships to define their identity and personality (Mellor et al., 2008). Consequently, social isolation may have negative consequences for mental health.

Studies conducted among individuals who have been isolated from others for long periods of time (e.g., solo sailors, scientific explorers, submariners) often report physical and psychological costs of social isolation (Coplan \& Bowker, 2013; Palinkas \& Suedfeld, 2008). Substantial scientific evidence has revealed that individuals lacking social relationships present public health problems and their risk of premature mortality increases (Cacioppo \& Hawkley, 2003; Hawkley \& Cacioppo, 2010; Holt-Lunstad et al., 2015). In their metaanalysis, Holt-Lunstad et al. (2015) showed that social isolation is associated with poor health behaviours (e.g., smoking and obesity), and may lead to adverse psychological effects such as anxiety, depression, and boredom.

In addition to effects on mental health, social isolation could also affect social behaviours and performance in cognitive tasks. In a series of experiments, Baumeister et al. (Baumeister et al., 2002) showed that participants who anticipated a "solitary future" developed more aggressive behaviours than those who did not. They also demonstrated that their performance was negatively affected on cognitive tasks, and complex attention and memorization tests (Twenge et al., 2007). One of the main limitations of these studies is that individuals, for ethical reasons, were not placed in real situations of lockdown or durable social isolation. In this sense, the recent enforced stay-at-home associated with the COVID-19 outbreak provides a never before encounter situation to study the psychological effects of forced and prolonged social isolation. Although social isolation has been recognized to have negative effects, it may also have positive effects (Coplan \& Bowker, 2013; Palinkas \& Suedfeld, 2008). 


\section{The positive effects of social isolation}

It is commonly admitted that social isolation is an objective state which can influence individuals' social behaviours and psychological outcomes. However, as claimed by Rosedale (2007), it is important to consider how individuals perceive the experience of being lonely. With this consideration in mind, isolation is an 'objective' state of being separate from others, while loneliness is a 'subjective' isolation of individuals regarding their aspirations for social relationships and what they actually have in terms of social and emotional relationships (Peplau \& Perlman, 1982). Researchers have proposed distinguishable positive and negative experiences of solitude organized around three dimensions: (1) self-discovery, creativity and problem-solving, (2) loneliness and diversion, (3) intimacy and spirituality (Long et al., 2003). Considering the different experiences of solitude, social isolation may allow individuals to grow, develop deeper connections and insight, and become more creative (Long \& Averill, 2003). As solitude affords freedom of spirit, and is often associated with a state of boredom conducive to creativity (Farmer \& Sundberg, 1986; Mann \& Cadman, 2014), it may facilitate self-reflection and contemplation (Koch, 1994) and foster creative thinking in various domains (Simonton, 2000, 2004). Many great works of art, philosophy, literature, science have emerged from solitude (Banerjee \& Rai, 2020), and one part of the personality of creators refers to a preference for solitude originating in childhood, and often leading to a deliberate attempt to seek solitude (Ochse, 1990). Solitude was a prerequisite to being creative, as it helps the individual to experience nonconformity and gather different ideas needed to create (Tick, 1988). Similarly, Csikszentmihalyi (1997) found that adolescents who could not tolerate being alone often failed to develop their creative talents because such development usually relies on solitary activities. Additionally, it was shown that those who spent about $30 \%$ of their waking time alone tended to show better psychological adjustment 
than those who were either never alone or spent a long time alone (Larson \& Csikszentmihalyi, 1978).

To date, research on the effects of social isolation has yielded contradictory findings probably due to the relatively short isolation periods, but also to individual differences promoting resilience. Thus, it is important to improve our knowledge of personality and individual differences to enable people at risk during a forced and prolonged quarantine to be identified.

\section{The role of the preference for solitude and personality variables}

Winnicott (1958) already suggested that the goal for individuals was not to overcome solitude, but to learn to tolerate it. He found that people with a secure attachment style were best able to benefit from solitude. Long et al. (2003) subsequently showed that experiences of solitude may be positive or negative, depending on the context and a large number of personality variables such as attachment style, neuroticism, low self-esteem, extraversion and preference for solitude. According to Long et al. (2003), the Preference for Solitude Scale (Burger, 1995) is "the only scale designed explicitly to measure individual differences in the capacity for solitude" (p. 583). The preference to be alone is determined either as a means of coping with social anxiety and shyness, or in order to liberate time for self-reflection and pleasurable activities, notably creative ones (Burger, 1995). Most research has revealed that a preference to spend time alone instead of with others is often associated with psychological problems such as social anxiety and shyness (Leary, 1983), and poor social skills (Sloan \& Solano, 1984). Alternatively, the preference for solitude is also associated with positive experiences such as privacy, relaxation, self-reflection, creativity and emotional regulation (Long et al., 2003; Nguyen et al., 2018). Similarly, comfort with solitude and time spent alone is sometimes related to well-being (Larson \& Lee, 1996). Thus, experiences of solitude could 
be either negative or positive depending on the individual's preference for solitude. During lockdown, some people could have experienced isolation as a positive experience that liberated them and led to enriching creative activities, while others may have perceived this period as stressful, cutting them off from friends and family. A study among Italians in the early phase of the COVID-19 outbreak demonstrated that depression and insecure-anxious attachment style predicted deterioration in mental health (Moccia et al., 2020).

As the experiences of social isolation during lockdown could be affected by individual differences, it is important to understand more clearly how people react to such a situation. In this perspective, it seems necessary to extend research to: (1) examine individuals' reactions to isolation according to their preference for solitude, (2) identify psychological profiles of individuals at risk from social isolation during pandemic lockdowns, and (3) examine if distinct personality profiles affect individuals' mental health and creativity during lockdown, that is to say being forced to stay at home.

Based on the literature, we expected that individuals characterized by high levels of preference for solitude would be less at risk of negative effects of social isolation associated with lockdown, i.e., less stressed, anxious and loneliness, and more creative. Because of their relationships to the preference for solitude and mental health, the potential effects of Big Five dimensions of personality were controlled in this study.

\section{Method}

\section{Participants}

Participants completed an anonymous online survey, after having read the written consent form and explicitly agreeing to participate. There was no monetary or credit compensation. The study was conducted in accordance with the Declaration of Helsinki, and 
was approved by the Ethics Committee of the University. The survey was shared via social media from Avril $14^{\text {th }}$ to Avril $29^{\text {th }} 2020$. A total of 438 participants living in metropolitan France completed the survey.

\section{Procedure}

The self-report questionnaire was set up to collect sociodemographic variables (age, gender, educational level and occupation), information on lockdown conditions (type of accommodation, living alone or with family, and frequency of face-to-face and online contacts), measures of preference for solitude and Big Five personality, measures of mental health (anxiety, stress and feelings of loneliness), and creativity (divergent and convergent creative thinking tasks). Participants were invited to answer the questionnaire in a quiet place and alone. They filled in the questionnaire from the $29^{\text {th }}$ to the $44^{\text {th }}$ day of the 55 days of the first lockdown in France $(M=31.6, S D=3.29)$.

\section{Measures}

The questionnaire was in French and was made up of very brief measures for use in large online surveys which are known to have good validity and reliability across different samples.

Preference for solitude. We used the Preference for Solitude Scale (PSS) (Burger, 1995; Cramer \& Lake, 1998). The PSS was translated into French by two native French speakers who were psychology experts. It was then back-translated by a professional translator, and modifications were made in order to ensure that the meaning of the original items remained similar to the translated version. This scale comprises 12 forced-choice statements. One option reflects a preference for solitude (coded 1) and the other a preference for being with other people (coded 0). Sample items include "I enjoy being around people vs I 
enjoy being by myself" and "Time spend alone is often productive for me $v s$ Time spend alone is often time wasted for me." The global score of preference for solitude was calculated from the sum of the 12 items. The factor structure of the PSS varied from one factor (Burger, $1995)$ to three factors (Cramer \& Lake, 1998). We compared the one-factor model $\left(\chi^{2}(54)=\right.$ $155, p<.001, \mathrm{TLI}=.85, \mathrm{CFI}=0.88, \mathrm{SRMR}=0.05, \mathrm{RMSEA}=.06)$, and the three factormodel $(\chi 2(51)=81.4, p<.005, \mathrm{TLI}=.95, \mathrm{CFI}=0.96, \mathrm{SRMR}=0.04, \mathrm{RMSEA}=0.04)$. If the fit indices seem slightly better for the three-factor model, the adjustment of this model was not better than the one-factor model (BICs $=5998$ and 6054, respectively). Moreover, the internal consistency of the three-factor model was not satisfactory for each subscale (Need for solitude, $\alpha=0.59$; Enjoy for solitude, $\alpha=0.67$; Productivity during solitude, $\alpha=0.61$ ). Thus, we used the one-factor structure as in Burger's PSS scale (Burger, 1995) with a good internal reliability $(\alpha=0.76)$.

Big-Five personality. We used the French version of the 10-Item Personality Inventory (TIPI) (Gosling et al., 2003; Storme et al., 2016). The TIPI is a very brief measure of the Big-Five personality dimensions with 10 items for use in large surveys. It allows the description of people's behavioural tendencies based on five independent traits: Extroversion, agreeableness, conscientiousness, emotional stability and openness to new experiences. Each item of the TIPI consists of two descriptors, separated by a comma (e.g., "I see myself as extraverted, enthusiastic'), Each item was rated on a seven-point Likert scale ranging from 1 (disagree strongly) to 7 (agree strongly). Each of the five dimensions was based on the mean of two items. The internal consistencies of Extroversion, Agreeableness, Conscientiousness, Emotional stability and Openness were reported as $0.63,0.32,0.32,0.64$ and 0.42 , respectively. As in the original scale of the TIPI, internal consistencies of agreeableness and conscientiousness subscales were not satisfactory. Moreover, we had a major problem of distribution of data for two items of these dimensions (skewness and kurtosis values $>+1$ or - 
1, see Supplementary Data on our OSF project page). Thus, agreeableness and conscientiousness dimensions were not used in further analyses.

Stress. We measured the perceived stress related to lockdown with a single item: "How do you currently feel about this lockdown situation?". Participants responded on a 10point scale ranging from 1 (not at all stressful) to 10 (very stressful). Higher scores revealed that individuals were stressed by the home confinement.

Anxiety. We used the French short form of the Spielberger State-Trait Anxiety Inventory (Gauthier \& Bouchard, 1993; Marteau \& Bekker, 1992). This scale is composed of three items representing no anxiety and three items representing the presence of anxiety. All items are rated on a four-point scale ranging from 1 (Almost never) to 4 (Almost always). Factor analyses confirmed the one-factor structure of this scale, $\chi^{2}(9)=30.4, p<.001(\mathrm{TLI}=$ $.97, \mathrm{CFI}=0.98, \mathrm{SRMR}=0.03, \mathrm{RMSEA}=.07)$ and the internal reliability was $\operatorname{good}(\alpha=$ 0.85). A global anxiety score was calculated by the sum of six items (with three reversed items) and the total score was multiplied by 20/6. According to Spielberger's (1983) manual, a 'normal' score is approximatively 34-36. Scores for people with diagnosed anxiety are between 47 and 61 .

Loneliness. We used the Three-Item Loneliness Scale (Hughes et al., 2004) adapted from the R-UCLA Loneliness Scale (Russell et al., 1980). We used this short scale adapted for phone or online surveys (sample item: “How often do you feel isolated from others?”). Participants responded on a four-point scale coded 1 (never), 2 (rarely), 3 (sometimes) and 4 (often). The internal consistency of this scale is good $(\alpha=0.71)$. Higher scores indicate a feeling of loneliness. 
Creativity. Both divergent and convergent thinking processes have been identified in the literature to measure creativity (Guilford, 1950). Divergent thinking is the ability to generate ideas or solutions to a problem that does not have a right or wrong answer. Convergent thinking is the ability to apply conventional and logical information search, recognition and decision-making strategies to find creative solutions to a problem having a correct answer. For example, solving an insight problem consists in finding the right and original answer to the problem because the first and most obvious solution is often wrong. With this distinction in mind, three different tasks were used to measure creativity.

The first was an idea-generation task measuring divergent thinking. It entailed producing as many different ways as possible to use a cardboard box. The number of ideas produced by each participant (fluency) was counted by two independent coders. As the intercoder agreement was highly satisfactory $(r=.97, p<.001)$, only the scores of the first coder were used.

Two other creativity tasks were used to measure convergent thinking, both of them requiring shifting one's perception of a problem and viewing it from a new perspective to find the solution (Dow \& Mayer, 2004; Duncker, 1945). The first convergent thinking task consisted of four insight problems (Webb et al., 2016), taken from prior studies and translated into French (Beaty et al., 2014; DeYoung et al., 2008; Dow \& Mayer, 2004; Michinov \& Michinov, 2020). A creativity score based on the number of correct answers to the task was calculated from 0 to 4 . The second convergent thinking task used four items of the Remote Associates Test (Mednick \& Mednick, 1967) which required finding one word that can be associated with the three words proposed by means of synonymy, formation of a compound word, and/or semantic association. For example, the words CREAM/SKATE/WATER are associated with ICE by means of synonymy (ice = water), formation of a compound word 
(ice-cream) and semantic association (ice skate). A score of creativity based on the number of correct answers was calculated from 0 to 4 (see Supplementary Material about insight tasks on our OSF project page). The participants were asked whether they had been helped by others while performing the creative thinking tasks.

\section{Data analysis}

Prior to analysis, preliminary assumption testing was conducted. We performed a “median-absolute detection" analysis for detecting outliers (Leys et al., 2013). The test revealed that eight participants had variation greater than 2.5 times the median absolute deviation for the fluency score, suggesting that we had outliers. Hence, the final sample for all analyses consisted of 430 participants. A sensitivity power analysis was conducted using G*Power (Faul et al., 2007). The sample size gave us 95\% power to detect effects of at least Cohen's $f^{2}=.05$ for the linear multiple regression, .15 for the MANOVA, and .19 for the ANOVA.

First, descriptive statistics and Pearson's correlations were summarized. We used $t$ tests and ANOVAs to examine the effects of sociodemographic characteristics and lockdown conditions on the variables studied. Second, multiple regression analyses were conducted to examine the relative contributions of preference for solitude and personality variables (i.e., emotional stability, extraversion and openness) on indicators of mental health (i.e., anxiety, stress and loneliness) and indicators of creativity (i.e., divergent and convergent creative thinking). To explore the data thoroughly, we used a person-centred approach to identify the psychological profiles that best support lockdown. For this, a data clustering technique was used. We conducted data grouping through a combination of hierarchical (using Ward's method) and non-hierarchical (i.e., K-means analysis) methods (Hair et al., 2010). As we used some different scales with different score ranges, all variables included were Z-scored. This 
transformation allows the same metric properties to be shared for each variable, enabling a reliable comparison. To determine whether potential risk profiles significantly differed on preference for solitude and personality variables, multivariate analysis of variance (MANOVA) were conducted. Finally, we examined the effects of the profiles on anxiety, stress, loneliness and creativity measures with omnibus analysis of variance (ANOVAs). Post-hoc tests were corrected for multiple comparisons with Bonferroni procedure when appropriated.

The data analyses were performed using Jamovi (Jamovi Project, 2020) and the 'Machine Learning' module (Clustering) of the JASP software (JASP Team, 2020).

\section{Results}

\section{Characterization of the sample}

Sociodemographic characteristics and participants' living arrangements are presented in Table 1. The majority of participants were females, relatively young, with a fairly high level of education, one half were employed and the other half were students, they lived either in a house or a flat with outdoor access, and more than half lived in a family with children. They have more online social contacts than face-to-face social contacts outside the home.

\section{Effects of sociodemographic characteristics and living arrangements on study variables}

We did not observe any effect of sociodemographic characteristics or participants' living conditions on the study variables, except for gender. Women reported higher levels of stress, $t(426)=3.57, p<.001, d=0.40$, anxiety, $t(426)=4.52, p<.001, d=0.50$ and emotional stability, $t(426)=-6.39, p<.001, d=0.71$, and they produced more ideas than men in the idea-generation task, $t(425)=2.39, p=.02, d=0.27$. Conversely, the preferences for 
solitude and introversion were higher among men than women, $t(426)=-2.09, p=.037, d=$ 0.23 and $t(426)=2.37, p=.018, d=0.26$ respectively. 


\section{Table 1}

Sociodemographic characteristics and participants' living arrangements

\begin{tabular}{|c|c|c|}
\hline \multirow[t]{3}{*}{ Gender } & Women & $74.7 \%$ \\
\hline & Men & $24.9 \%$ \\
\hline & Gender diverse & $0.5 \%$ \\
\hline \multirow[t]{4}{*}{ Age } & & $M=27.9$ \\
\hline & & $S D=11.6$ \\
\hline & & $\operatorname{Min}=17$ \\
\hline & & $\operatorname{Max}=75$ \\
\hline \multirow[t]{3}{*}{ Occupational activities } & Students & $48.8 \%$ \\
\hline & Employed & $42.3 \%$ \\
\hline & Unemployed & $8.8 \%$ \\
\hline \multirow[t]{4}{*}{ Level of education } & Lower level than Baccalaureate & $6 \%$ \\
\hline & Baccalaureate & $24.4 \%$ \\
\hline & Bachelor degree & $50 \%$ \\
\hline & Master's or higher level & $16.1 \%$ \\
\hline \multirow[t]{3}{*}{ Type of accommodation } & House & $55.4 \%$ \\
\hline & Flat & $19.5 \%$ \\
\hline & Semi-detached house & $25.1 \%$ \\
\hline Access outdoor & & $82.4 \%$ \\
\hline \multirow[t]{4}{*}{ Social context of living } & Family with children & $53 \%$ \\
\hline & With a partner & $25.1 \%$ \\
\hline & Flat-sharing & $11.2 \%$ \\
\hline & Alone & $10.7 \%$ \\
\hline \multirow[t]{4}{*}{ Number of people living at home } & & $M=3.06$ \\
\hline & & $S D=1.40$ \\
\hline & & $\operatorname{Min}=0$ \\
\hline & & $\operatorname{Max}=8$ \\
\hline \multirow[t]{2}{*}{ Social Contacts } & Face-to-Face & $M=2.27$ \\
\hline & Online & $M=4.51$ \\
\hline
\end{tabular}

Note. For frequency of social contacts, participants responded on a five-point scale from 1 (never) to 5 (several times a day). 


\section{Descriptive statistics and correlations between study variables}

Means and standard deviations for study variables and bivariate correlations are presented in Table 2. For the whole sample, the mean stress and loneliness levels were moderate, while the mean anxiety level was significantly higher than the 'normal' value (3436), $t(429)=11.9, p<.001$ (one-sample $t$ test), suggesting a detrimental effect of the lockdown on anxiety. It also appeared that the three indicators of mental health (anxiety, stress and loneliness) were positively correlated. The measures of creativity were positively correlated to each other, except for fluency and RAT scores (measuring divergent and convergent thinking, respectively). The preference for solitude was negatively associated with stress, anxiety and loneliness, suggesting that individuals who preferred solitude reported better psychological reactions to lockdown. The preference for solitude was also positively correlated with RAT scores. Finally, emotional stability was negatively correlated with scores of stress, anxiety, loneliness and fluency. Openness was positively correlated with fluency. 
SOCIAL ISOLATION DURING COVID-19 AND PERSONALITY PROFILES

\section{Table 2}

Descriptive statistics, reliabilities and correlations between measures

\begin{tabular}{|c|c|c|c|c|c|c|c|c|c|c|}
\hline & 1 & 2 & 3 & 4 & 5 & 6 & 7 & 8 & 9 & 10 \\
\hline 1. Stress & - & & & & & & & & & \\
\hline 2. Anxiety & $0.72 * * *$ & $(.86)$ & & & & & & & & \\
\hline 3. Loneliness & $0.42 * * *$ & $0.45 * * *$ & $(.71)$ & & & & & & & \\
\hline 4. Pref. Solitude & $-0.11^{*}$ & $-0.11^{*}$ & $-0.30 * * *$ & $(.76)$ & & & & & & \\
\hline 5. Extraversion & 0.01 & 0.02 & 0.09 & -0.42 & $(.63)$ & & & & & \\
\hline 6. Emotional Stability & $-0.33 * * *$ & $-0.51 * * *$ & $-0.28 * * *$ & 0.00 & 0.02 & $(.64)$ & & & & \\
\hline 7. Openness & -0.04 & 0.02 & 0.02 & -0.01 & $0.22 * * *$ & -0.02 & $(.42)$ & & & \\
\hline 8. Fluency & -0.02 & 0.02 & -0.07 & 0.06 & 0.01 & $-0.12 *$ & $0.11 *$ & - & & \\
\hline 9. Perf. Insight Problem & -0.09 & -0.03 & -0.06 & 0.06 & -0.03 & 0.05 & 0.02 & $0.15^{* *}$ & - & \\
\hline 10. Perf. Insight RAT & -0.06 & -0.04 & -0.08 & $0.12 *$ & -0.05 & 0.09 & -0.05 & 0.05 & $0.33 * * *$ & - \\
\hline Mean & 4.38 & 43 & 5.71 & 5.78 & 4.10 & 4.20 & 4.98 & 5.15 & 1.98 & 1.37 \\
\hline SD & 2.39 & 13.8 & 1.86 & 2.90 & 1.51 & 1.66 & 1.24 & 2.66 & 1.15 & 1.03 \\
\hline Min. value & 1 & 20 & 3 & 0 & 1 & 1 & 1.5 & 0 & 0 & 0 \\
\hline Max. value & 10 & 80 & 12 & 12 & 7 & 7 & 7 & 13 & 4 & 4 \\
\hline
\end{tabular}

Note. The Internal consistency coefficients (Omega coefficients) are on the diagonal. ${ }^{*} p<.05, * * p<.01, * * * p<.001 . N=430 . \mathrm{SD}=\mathrm{Standard}$ deviation. 


\section{Multiple regression analyses}

To analyse the respective effects of the preference for solitude and personality variables on mental health and creativity, multiple regression analyses were performed with personality dimensions and gender as control variables (see Table 3). Results showed that the gender variable did not explain any measures when the preference for solitude and personality variables were entered in the regression. Mental health (stress, anxiety and loneliness) was negatively associated with the preference for solitude and emotional stability scores. For creativity, RAT scores were positively linked to preference for solitude, and fluency scores were related to openness. 
Table 3

Multiple regression to test the relative contribution of demographic and personality variables on stress, anxiety, loneliness and creativity measures

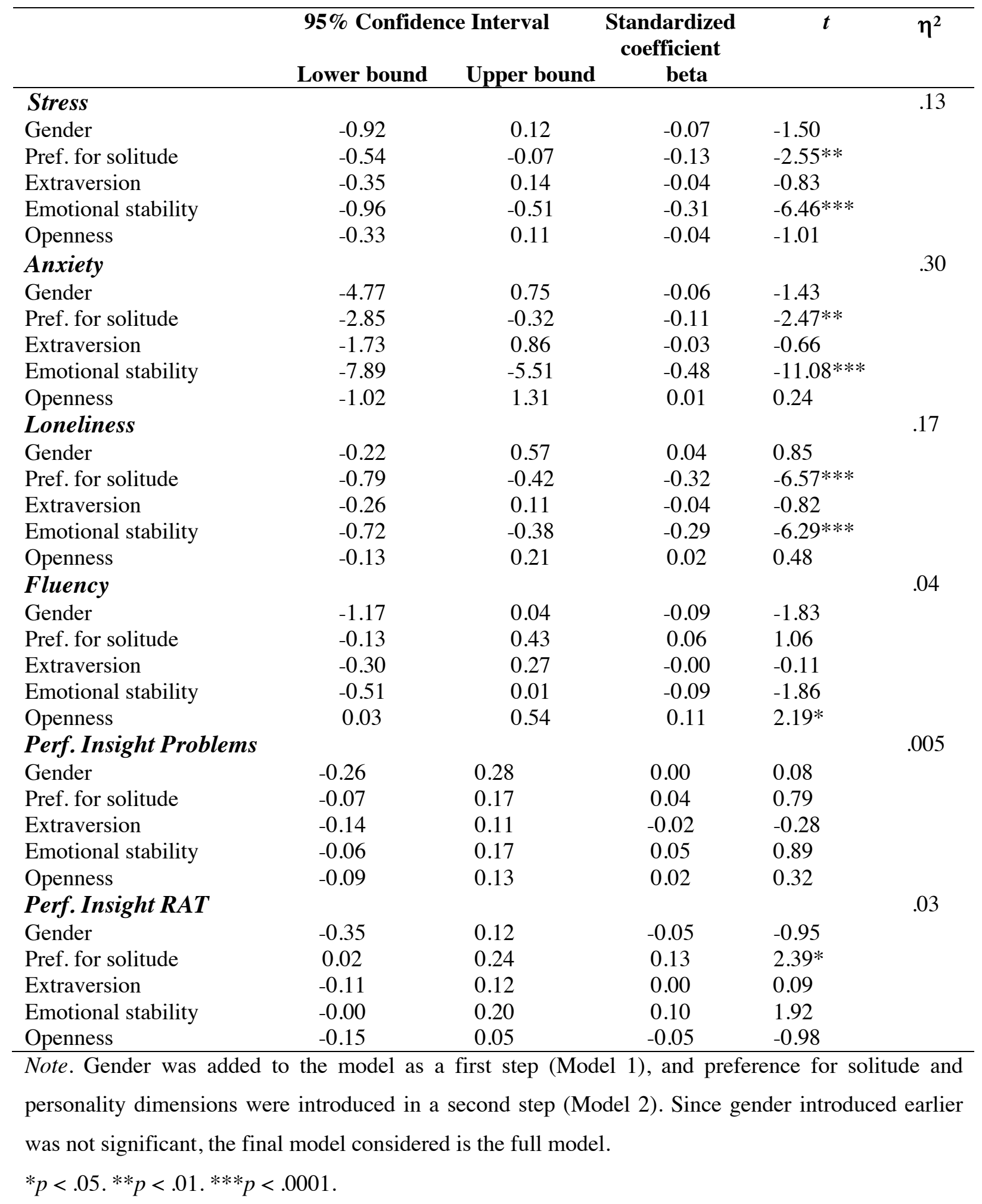




\section{Cluster analysis}

The first hierarchical cluster analysis (Wards' method) was performed on the four standardized scores of the preference for solitude and personality variables (i.e., extraversion, emotional stability and openness). The dendrogram analysis suggested the suitability of a 3cluster solution (see Figure 1).

\section{Figure 1}

\section{Dendrogram from a hierarchical cluster analysis}

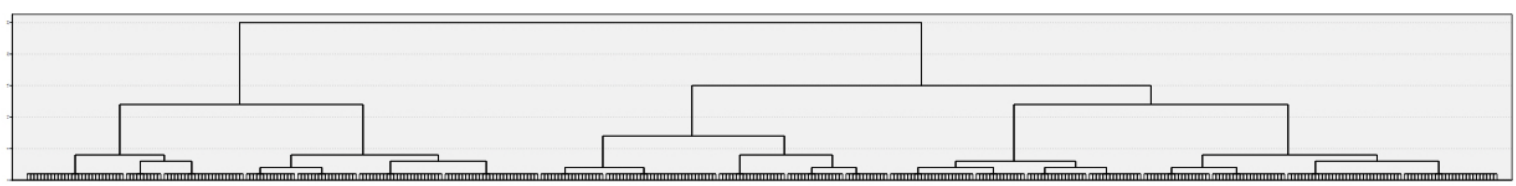

Inspection of the Silhouette plot showed that the silhouette coefficient was highest when $\mathrm{k}$ $=3$, suggesting that this was the "optimal" number of clusters. The second highest silhouette coefficient corresponded to $\mathrm{k}=4$. We then compared three solutions $(\mathrm{k}=1, \mathrm{k}=2$ and $\mathrm{k}=4)$ to form clusters with k-means analysis. The profile analysis identified three profile subgroups as the best solution (see the Supplementary data 2 on our OSF project page). The three-profile subgroup model (3-class solution) fits the data significantly better than the two-class solution and as well as the four-class solution considering the smaller BIC and AIC. The increment in model fit of the four-group model from the three-group model was not statistically significant. Thus, only the three-profile solution was retained for subsequent analyses because it was parsimonious and each profile accounted for $>10 \%$ of the participants (Hair et al., 2010).

Figure 2 describes the three personality profiles finally retained. Profile 1 was labelled "Affiliation" and was characterized by low preference for solitude, a high level of 
extraversion, a high level of emotional stability and a moderate level of openness. It concerned $42.1 \%$ of the sample. Profile 2, named "Emotionally Stable Lonely", was represented by high levels of preference for solitude and emotional stability, a low level of extraversion, and a moderate level of openness. This profile concerned $34.2 \%$ of the sample. Profile 3, named "Emotionally Unstable Lonely", was characterized by moderate levels of preference for solitude and extraversion, a low level of emotional stability, and a high level of openness. It concerned $23.7 \%$ of the sample. A Chi-square analysis showed that gender was not equally distributed across the three profiles, $\chi^{2}(2, N=428)=22.7, p<.001, \phi=.23$.

Females were over-represented in Profile 1 "Affiliation" and Profile 3 "Emotionally Unstable Lonely". The cluster characteristics are shown in the Supplementary data on our OSF project page.

\section{Figure 2}

Three profiles based on personality variables

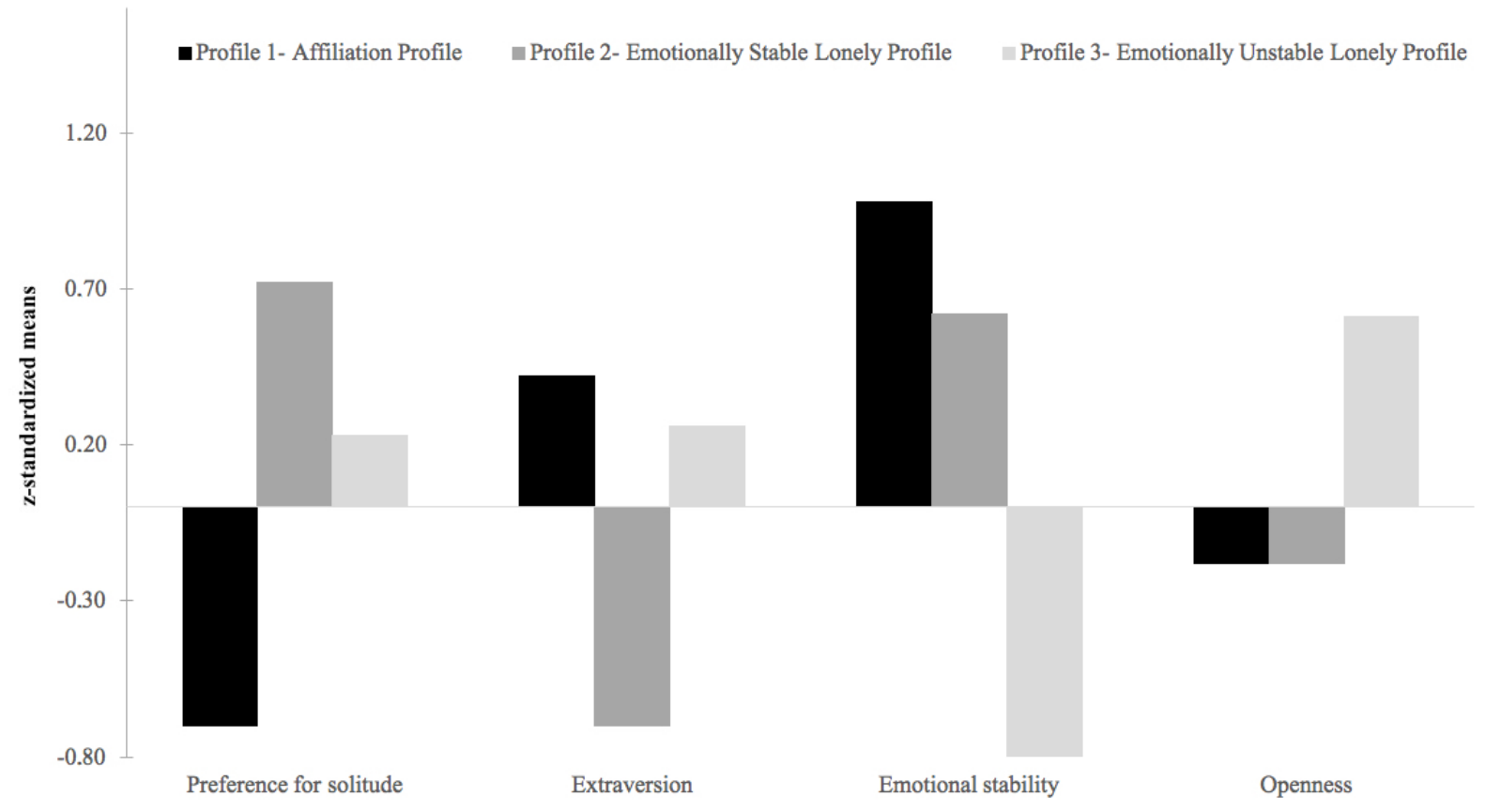


SOCIAL ISOLATION DURING COVID-19 AND PERSONALITY PROFILES

A MANOVA was conducted with cluster membership as the independent variable and the four personality variables as dependent variables. The overall model was significant, revealing that each personality variable appeared to vary significantly between clusters (Wilks' $\left.\Lambda=.24, F(8,848)=112, p<.0001, \eta^{2}=.513\right)$. Post-hoc tests revealed significant differences between the three profiles with regard to the preference for solitude and emotional stability. Profiles 1 and 2 did not differ with regard to openness, and profiles 1 and 3 did not differ with regard to extraversion (see Table 4).

Then, to identify a profile of individuals at risk during a period of lockdown, ANOVAs were conducted with cluster membership as the independent variable and mental health and creativity measures as dependent variables. With regard to mental health measures, results showed significant differences between the three clusters for stress, anxiety and loneliness scores. Post-hoc tests showed that the individuals with an "Emotionally Unstable Lonely" profile reported more stress and higher anxiety levels than the two other profiles. Interestingly, it also appeared that the lower levels of loneliness reported concerned the individuals with an "Emotionally Stable Lonely" profile with high levels of preference for solitude and emotional stability. As regards the effects of clusters on creativity, results showed significant differences between two profiles: higher scores for the RAT tests were found for individuals with an "Emotionally stable Lonely" profile than for those with an “Emotionally Unstable Lonely" profile. Conversely, individuals with an "Emotionally Unstable Lonely" profile characterized by a high level of openness to experiences produced significantly more ideas than those with an "Emotionally stable Lonely" profile. No difference between the three profiles was found for performance on the insight problems. 
SOCIAL ISOLATION DURING COVID-19 AND PERSONALITY PROFILES

\section{Table 4}

Mean differences and Standard Deviations (SD) in study variables among the three profiles

\begin{tabular}{|c|c|c|c|c|c|c|}
\hline & $\begin{array}{c}\text { Profile } 1 \\
\text { Mean (SD) }\end{array}$ & $\begin{array}{c}\text { Profile } 2 \\
\text { Mean (SD) }\end{array}$ & $\begin{array}{c}\text { Profile } 3 \\
\text { Mean (SD) }\end{array}$ & $F$ & $p$ & $\eta^{2}$ \\
\hline \multicolumn{7}{|l|}{ Personality variables } \\
\hline Preference for solitude & $3.74^{\mathrm{a}}(1.92)$ & $7.84^{\mathrm{b}}(2.24)$ & $6.43^{\mathrm{c}}(2.80)$ & 139.08 & $<.001$ & .39 \\
\hline Extraversion & $4.73^{\mathrm{a}}(1.35)$ & $3.04^{\mathrm{b}}(1.11)$ & $4.49^{\mathrm{a}}(1.48)$ & 73.27 & $<.001$ & .26 \\
\hline Emotional Stability & $4.36^{\mathrm{a}}(1.37)$ & $5.24^{\mathrm{b}}(1.31)$ & $2.42^{\mathrm{c}}(1.02)$ & 150 & $<.001$ & .41 \\
\hline Openness & $4.74^{\mathrm{a}}(1.07)$ & $4.74^{\mathrm{a}}(1.49)$ & $5.73^{\mathrm{b}}(0.71)$ & 27.53 & $<.001$ & .11 \\
\hline \multicolumn{7}{|l|}{ Outcomes variables } \\
\hline Stress & $4.35^{\mathrm{a}}(2.28)$ & $3.86^{\mathrm{a}}(2.15)$ & $5.18^{\mathrm{b}}(2.67)$ & 8.62 & $<.001$ & .04 \\
\hline Anxiety & $43.00^{\mathrm{a}}(13.2)$ & $38.2^{\mathrm{b}}(11.9)$ & $49.9^{\mathrm{c}}(14.7)$ & 22.6 & $<.001$ & .10 \\
\hline Loneliness & $5.90^{\mathrm{a}}(1.84)$ & $5.17^{\mathrm{b}}(1.56)$ & $6.16^{\mathrm{a}}(2.12)$ & 11.4 & $<.001$ & .05 \\
\hline Fluency & $5.17^{\mathrm{a}}(2.69)$ & $4.78^{\mathrm{a}}(2.56)$ & $5.66^{\mathrm{ab}}(2.68)$ & 3.39 & .035 & .02 \\
\hline Perf. Insight Problems & $2.10(1.10)$ & $1.92(1.22)$ & $1.83(1.12)$ & 2.09 & .13 & .009 \\
\hline Perf. Insight RAT & $1.35^{\mathrm{a}}(1.01)$ & $1.52^{\mathrm{a}}(1.09)$ & $1.19^{\mathrm{ab}}(0.96)$ & 3.20 & .043 & .02 \\
\hline$\%$ of Female & $79 \%$ & $61.9 \%$ & $87 \%$ & 22.7 & .001 & - \\
\hline
\end{tabular}

Notes. Profile 1 = Affiliation Profile; Profile 2 = Emotionally Stable Lonely Profile; Profile 3 = Emotionally Unstable Lonely Profile.

Gender is coded as $1=$ Male, $0=$ Female (Chi-square analysis). Different subscripts in a row indicate significant differences. 


\section{Discussion}

The COVID-19 outbreak required people to drastically reduce social contacts by staying at home. Although prior research suggested that social isolation affects mental and physical health (Brooks et al., 2020; Taylor et al., 2008), it was expected that the reactions may vary depending on individuals. Recent research has begun to explore the effects of sociodemographic or individual difference variables on vulnerability to social isolation (Liu et al., 2020; Moccia et al., 2020; Roychowdhury, 2020). The present study aimed to examine the relationships between personality variables (Preference for the solitude and Big Five dimensions), individuals' mental health and creativity during the first forced long period of lockdown in France. Moreover, this study aimed to identify a personality profile susceptible to influence individuals' mental health and creativity during lockdowns.

The results reveal, on the one hand, that the overall sample showed an average anxiety state that was higher than the normal reference value, suggesting population concern about the quarantine, in line with other studies during disease epidemics (Brooks et al., 2020; Taylor et al., 2008). On the other hand, perceived stress and loneliness associated to lockdown were moderate. Similar results were observed for online surveys conducted on the Chinese and Italian population during the COVID-19 outbreak (Liu et al., 2020; Moccia et al., 2020). This may be due to the still relatively short exposure period of the epidemic, and also to individual characteristics promoting resilience. The present results suggest the existence of specific profiles of individuals at risk during a period of lockdown. Firstly, although we observe that women generally tend to report more stress and anxiety than men during epidemic diseases (Liu et al., 2020; Taylor et al., 2008), this gender effect disappeared when individual differences related to the preference for solitude and personality variables were considered, as shown by the multiple regression. 
The main findings of this study reveal the existence of three personality profiles: individuals who preferred affiliation (“affiliative"), individuals who were emotionally stable, introverted, and preferred solitude to having positive experiences ("Emotionally Stable Lonely"), and individuals who were unstable emotionally and preferred solitude to cope with social anxiety ("Emotionally Unstable Lonely"). These results provide further support to previous studies showing both positive and negative experiences of solitude (Larson \& Lee, 1996; Long et al., 2003), as well as the existence of two profiles of preference for solitude (Burger, 1995). Moreover, interestingly, this study reveals that these personality profiles affected the mental health of individuals during lockdown. Thus, perceived stress and anxiety were higher among people with a need for affiliation and in those with an emotionally unstable preference for solitude. By contrast, emotionally stable individuals, who were introverted and preferred solitude, experienced less loneliness than the other two profiles. As expected, individuals tolerated the social isolation of lockdown differently. Similarly, the individuals who preferred solitude for positive reasons, were more creative for one of the two convergent creative thinking tasks, the Remote Associates Test, during the experience of lockdown than the other personality profiles. However, individuals with an "Emotionally Unstable Lonely" profile with openness to experience, performed better for divergent creative thinking tasks. As convergent thinking tasks such as RAT require introspection and selfreflection, individuals with an "Emotionally Stable Lonely" profile characterized by high introversion were more creative on these tasks. This result is in line with studies suggesting a relationship between introversion and creativity (Bowker et al., 2017; Csikszentmihalyi, 1997; Feist, 1998). According to Feist (1998), the most creative people are those who are introverted and who are comfortable working in solitary (and social isolation) situations in which they can focus attention inward. However, it is worth noting that there is no significant effect on performance to insight problems (see also Karwowski et al., 2020). Conversely, as 
divergent thinking tasks require open-mindedness and getting out of the box, individuals with an "Emotionally Unstable Lonely" profile characterized by high openness were more creative on these tasks. This result is in line with research that shows that openness to experiences has been closely related to creativity, and specifically to divergent thinking (Coursey et al., 2018; King et al., 1996; McCrae, 1987). In using 'objective' creativity measures, our results complete a recent study revealing that everyday creativity subjectively measured by an online questionnaire increased during the first lockdown in France (Mercier et al., 2021). Taken together, these findings demonstrated that experience of solitude during lockdown may have different benefits or costs according to the personality profiles.

\section{Limitations}

This study is not without limitations. First, the cross-sectional study used a correlational design that does not allow for causal relationships to be identified. A longitudinal design would have been interesting, but we could not use this design since the duration of the lockdown period was not known at the beginning of the study. Secondly, this study involves a sample that may not be representative of the worldwide population. Due to demographic characteristics of the sample, and notably a greater proportion of women, relatively young respondents and participants with higher-than-average levels of education, it is possible that there could have been a response bias in the data. As in other studies, the high proportion of women may be due to their greater interest and participation in such online studies (Taylor et al., 2008). However, the characteristics of our sample may be a strength as the effects of social isolation have mainly been focused on the elderly and vulnerable groups. Finally, the geographical area restricted to France also limits the generalizability of the results to other countries where strict lockdown was imposed. 


\section{Conclusion}

This study contributes further to the investigation of individual differences when facing strict lockdown over a long period (Moccia et al., 2020). The present findings revealed that individuals' preference for solitude, emotional stability, extraversion and openness to new experience may help to predict mental health and creativity in a forced prolonged lockdown period. These results echo with recent studies that have recommended offering interventions and activities to individuals to deal with the social isolation caused by lockdown (Brooks et al., 2020; Roychowdhury, 2020). Thus, specific activities matching each personality profile could be proposed. For example, social support using a telephone support line or social media could be proposed to individuals with an "Affiliative" profile; activities that require attention to details could be appropriate for "Emotionally Stable Lonely" individuals; distractive or open mind activities may lead "Emotionally Unstable Lonely" individuals to thrive in solitude. These recommendations are in line with those of the World Health Organization (2020), "during times of stress, pay attention to your needs and feelings. Engage in healthy activities that you enjoy and find relaxing” (p.5). To finish, this study has the merit of going further than previous studies which highlighted the need to take into account the vulnerabilities of certain communities or groups (women experiencing domestic violence, people with disabilities, people of colour, homeless, refugee, etc.) (Bu et al., 2020; Roychowdhury, 2020). 


\section{References}

Bacon, A. M., \& Corr, P. J. (2020). Coronavirus (COVID-19) in the United Kingdom: A personality-based perspective on concerns and intention to self-isolate. British Journal of Health Psychology, bjhp.12423. https://doi.org/10.1111/bjhp.12423

Banerjee, D., \& Rai, M. (2020). Social isolation in Covid-19: The impact of loneliness. International Journal of Social Psychiatry, 66(6), 525-527. https://doi.org/10.1177/0020764020922269

Baumeister, R. F., \& Leary, M. R. (1995). The need to belong: Desire for interpersonal attachments as a fundamental human motivation. Psychological Bulletin, 117(3), 497529. https://doi.org/10.1037/0033-2909.117.3.497

Baumeister, R. F., Twenge, J. M., \& Nuss, C. K. (2002). Effects of social exclusion on cognitive processes: Anticipated aloneness reduces intelligent thought. Journal of Personality and Social Psychology, 83(4), 817-827. https://doi.org/10.1037/00223514.83.4.817

Beaty, R. E., Nusbaum, E. C., \& Silvia, P. J. (2014). Does insight problem solving predict real-world creativity? Psychology of Aesthetics, Creativity, and the Arts, 8(3), 287-292. https://doi.org/10.1037/a0035727

Bowker, J. C., Stotsky, M. T., \& Etkin, R. G. (2017). How BIS/BAS and psycho-behavioral variables distinguish between social withdrawal subtypes during emerging adulthood. Personality and Individual Differences, 119, 283-288. https://doi.org/10.1016/j.paid.2017.07.043

Brooks, S. K., Webster, R. K., Smith, L. E., Woodland, L., Wessely, S., Greenberg, N., \& Rubin, G. J. (2020). The psychological impact of quarantine and how to reduce it: Rapid review of the evidence. The Lancet, 395(10227), 912-920. https://doi.org/10.1016/S0140-6736(20)30460-8 
Bu, F., Steptoe, A., \& Fancourt, D. (2020). Who is lonely in lockdown? Cross-cohort analyses of predictors of loneliness before and during the COVID-19 pandemic. Public Health, 186, 31-34. https://doi.org/10.1016/j.puhe.2020.06.036

Burger, J. M. (1995). Individual differences in preference for solitude. Journal of Research in Personality, 29(1), 85-108. https://doi.org/10.1006/jrpe.1995.1005

Cacioppo, J. T., Fowler, J. H., \& Christakis, N. A. (2009). Alone in the crowd: The structure and spread of loneliness in a large social network. Journal of Personality and Social Psychology, 97(6), 977-991. https://doi.org/10.1037/a0016076

Cacioppo, J. T., \& Hawkley, L. C. (2003). Social isolation and health, with an emphasis on underlying mechanisms. Perspectives in Biology and Medicine, 46(3), S39-S52. https://doi.org/10.1353/pbm.2003.0049

Coplan, R. J., \& Bowker, J. C. (Eds.). (2013). The Handbook of solitude: Psychological perspectives on social isolation, social withdrawal, and being alone (1st ed.). Wiley. https://doi.org/10.1002/9781118427378

Coursey, L., Paulus, P. B., Kenworthy, J., \& Williams, B. (2018). The role of individual differences in group and team creativity. In R. Reiter-Palmon \& J. Kaufman (Eds.), Individual creativity in the workplace (pp. 311-338). Elsevier.

Cramer, K. M., \& Lake, R. P. (1998). The preference for Solitude Scale: Psychometric properties and factor structure. Personality and Individual Differences, 24(2), 193-199. https://doi.org/10.1016/S0191-8869(97)00167-0

Csikszentmihalyi, M. (1997). Creativity: Flow and the psychology of discovery and invention (pp. viii, 456). HarperCollins Publishers.

Deci, E. L., \& Ryan, R. M. (1991). A motivational approach to self: Integration in personality. In Nebraska Symposium on Motivation, 1990: Perspectives on motivation (pp. 237288). University of Nebraska Press. 
DeYoung, C. G., Flanders, J. L., \& Peterson, J. B. (2008). Cognitive abilities involved in insight problem solving: An individual differences model. Creativity Research Journal, 20(3), 278-290. https://doi.org/10.1080/10400410802278719

Dow, G. T., \& Mayer, R. E. (2004). Teaching students to solve insight problems: Evidence for domain specificity in creativity training. Creativity Research Journal, 16(4), 389398. https://doi.org/10.1080/10400410409534550

Duncker, K. (1945). On problem-solving. (L. S. Lees, Trans.). Psychological Monographs, 58(5), i-113. https://doi.org/10.1037/h0093599

Farmer, R., \& Sundberg, N. D. (1986). Boredom proneness: The development and correlates of a new scale. Journal of Personality Assessment, 50(1), 4-17. https://doi.org/10.1207/s15327752jpa5001_2

Faul, F., Erdfelder, E., Lang, A.-G., \& Buchner, A. (2007). G*Power 3: A flexible statistical power analysis program for the social, behavioral, and biomedical sciences. Behavior Research Methods, 39(2), 175-191. https://doi.org/10.3758/BF03193146

Feist, G. J. (1998). A meta-analysis of personality in scientific and artistic creativity. Personality and Social Psychology Review, 2(4), 290-309. https://doi.org/10.1207/s15327957pspr0204_5

Gauthier, J., \& Bouchard, S. (1993). Adaptation canadienne-française de la forme révisée du State-Trait Anxiety Inventory de Spielberger. Canadian Journal of Behavioural Science / Revue Canadienne Des Sciences Du Comportement, 25(4), 559-578. https://doi.org/10.1037/h0078881

Gosling, S. D., Rentfrow, P. J., \& Swann, W. B. (2003). A very brief measure of the Big-Five personality domains. Journal of Research in Personality, 37(6), 504-528. https://doi.org/10.1016/S0092-6566(03)00046-1

Guilford, J. P. (1950). Creativity. American Psychologist, 5(9), 444-454. 
https://doi.org/10.1037/h0063487

Hair, J. F., Black, W. C., Babin, B. J., \& Anderson, R. E. (2010). Multivariate data analysis: A global perspective. Pearson Education.

Hawkley, L. C., \& Cacioppo, J. T. (2010). Loneliness matters: A theoretical and empirical review of consequences and mechanisms. Annals of Behavioral Medicine, 40(2), 218227. https://doi.org/10.1007/s12160-010-9210-8

Holt-Lunstad, J., Smith, T. B., Baker, M., Harris, T., \& Stephenson, D. (2015). Loneliness and social isolation as risk factors for mortality: A meta-analytic review. Perspectives on Psychological Science, 10(2), 227-237. https://doi.org/10.1177/1745691614568352

Hughes, M. E., Waite, L. J., Hawkley, L. C., \& Cacioppo, J. T. (2004). A short scale for measuring loneliness in large surveys: Results from two population-based studies. Research on Aging, 26(6), 655-672. https://doi.org/10.1177/0164027504268574

JASP Team (0.12.2). (2020). [Computer software]. https://jasp-stats.org

Jetten, J., Reicher, S., Haslam, A., \& Cruwys, T. (Eds.). (2020). Together Apart: The psychology of COVID-19. Sage Publishing. https://www.socialsciencespace.com/2020/05/addressing-the-psychology-of-togetherapart-free-book-download

Karwowski, M., Groyecka-Bernard, A., Kowal, M., \& Sorokowski, P. (2020). Does thinking about coronavirus impact insight and analytical reasoning? Thinking Skills and Creativity, 38, 100715. https://doi.org/10.1016/j.tsc.2020.100715

King, L. A., Walker, L. M., \& Broyles, S. J. (1996). Creativity and the five-factor model. Journal of Research in Personality, 30(2), 189-203. https://doi.org/10.1006/jrpe.1996.0013

Koch, P. (1994). Solitude: A philosophical encounter. Open Court. Larson, R., \& Csikszentmihalyi, M. (1978). Experiential correlates of time alone in 
adolescence. Journal of Personality, 46(4), 677-693. https://doi.org/10.1111/j.14676494.1978.tb00191.x

Larson, R., \& Lee, M. (1996). The capacity to be alone as a stress buffer. The Journal of Social Psychology, 136(1), 5-16. https://doi.org/10.1080/00224545.1996.9923024

Leary, M. R. (1983). Social anxiousness: The construct and its measurement. Journal of Personality Assessment, 47(1), 66-75. https://doi.org/10.1207/s15327752jpa4701_8

Leys, C., Ley, C., Klein, O., Bernard, P., \& Licata, L. (2013). Detecting outliers: Do not use standard deviation around the mean, use absolute deviation around the median. Journal of Experimental Social Psychology, 49(4), 764-766.

https://doi.org/10.1016/j.jesp.2013.03.013

Liu, N., Zhang, F., Wei, C., Jia, Y., Shang, Z., Sun, L., Wu, L., Sun, Z., Zhou, Y., Wang, Y., \& Liu, W. (2020). Prevalence and predictors of PTSS during COVID-19 outbreak in China hardest-hit areas: Gender differences matter. Psychiatry Research, 287, 112921. https://doi.org/10.1016/j.psychres.2020.112921

Long, C. R., \& Averill, J. R. (2003). Solitude: An exploration of benefits of being alone. Journal for the Theory of Social Behaviour, 33(1), 21-44. https://doi.org/10.1111/14685914.00204

Long, C. R., Seburn, M., Averill, J. R., \& More, T. A. (2003). Solitude experiences: Varieties, settings, and individual differences. Personality and Social Psychology Bulletin, 29(5), 578-583. https://doi.org/10.1177/0146167203029005003

Mann, S., \& Cadman, R. (2014). Does being bored make us more creative? Creativity Research Journal, 26(2), 165-173. https://doi.org/10.1080/10400419.2014.901073

Markus, H. R., \& Kitayama, S. (1991). Culture and the self: Implications for cognition, emotion, and motivation. Psychological Review, 98(2), 224-253. https://doi.org/10.1037/0033-295X.98.2.224 
Marteau, T. M., \& Bekker, H. (1992). The development of a six-item short-form of the state scale of the Spielberger State-Trait Anxiety Inventory (STAI). British Journal of Clinical Psychology, 31(3), 301-306. https://doi.org/10.1111/j.20448260.1992.tb00997.x

McCrae, R. R. (1987). Creativity, divergent thinking, and openness to experience. Journal of Personality and Social Psychology, 52(6), 1258-1265. https://doi.org/10.1037/00223514.52.6.1258

Mednick, S. A., \& Mednick, M. T. (1967). Examiner's manual, Remote Associates Test: College and adult forms 1 and 2. Houghton Mifflin Company, 2 Park St.

Mellor, D., Stokes, M., Firth, L., Hayashi, Y., \& Cummins, R. (2008). Need for belonging, relationship satisfaction, loneliness, and life satisfaction. Personality and Individual Differences, 45(3), 213-218. https://doi.org/10.1016/j.paid.2008.03.020

Mercier, M., Vinchon, F., Pichot, N., Bonetto, E., Bonnardel, N., Girandola, F., \& Lubart, T. (2021). Covid-19: A boon or a bane for creativity? Frontiers in Psychology, 11, 601150. https://doi.org/10.3389/fpsyg.2020.601150

Michinov, N., \& Michinov, E. (2020). Do open or closed postures boost creative performance? The effects of postural feedback on divergent and convergent thinking. Psychology of Aesthetics, Creativity, and the Arts. https://doi.org/10.1037/aca0000306 Moccia, L., Janiri, D., Pepe, M., Dattoli, L., Molinaro, M., De Martin, V., Chieffo, D., Janiri, L., Fiorillo, A., Sani, G., \& Di Nicola, M. (2020). Affective temperament, attachment style, and the psychological impact of the COVID-19 outbreak: An early report on the Italian general population. Brain, Behavior, and Immunity, 87, 75-79. https://doi.org/10.1016/j.bbi.2020.04.048

Nguyen, T. T., Ryan, R. M., \& Deci, E. L. (2018). Solitude as an approach to affective selfregulation. Personality and Social Psychology Bulletin, 44(1), 92-106. 
https://doi.org/10.1177/0146167217733073

Ochse, R. (1990). Before the gates of excellence: The determinants of creative genius (pp. ix, 300). Cambridge University Press.

Palinkas, L. A., \& Suedfeld, P. (2008). Psychological effects of polar expeditions. The Lancet, 371(9607), 153-163. https://doi.org/10.1016/S0140-6736(07)61056-3

Peplau, L. A., \& Perlman, D. (1982). Perspectives on loneliness. In L. A. Peplau \& D. Perlman (Eds.), Loneliness: A sourcebook of current theory, research and therapy (pp. 1-18). John Wiley \& Sons.

Pietrabissa, G., \& Simpson, S. G. (2020). Psychological consequences of social isolation during covid-19 outbreak. Frontiers in Psychology, 11. https://doi.org/10.3389/fpsyg.2020.02201

Rosedale, M. (2007). Loneliness: An exploration of meaning. Journal of the American Psychiatric Nurses Association, 13(4), 201-209. https://doi.org/10.1177/1078390307306617

Roychowdhury, D. (2020). 2019 novel coronavirus disease, crisis, and isolation. Frontiers in Psychology, 11, 1958. https://doi.org/10.3389/fpsyg.2020.01958

Russell, D., Peplau, L. A., \& Cutrona, C. E. (1980). The revised UCLA Loneliness Scale: Concurrent and discriminant validity evidence. Journal of Personality and Social Psychology, 39(3), 472-480. https://doi.org/10.1037/0022-3514.39.3.472

Sibley, C. G., Greaves, L. M., Satherley, N., Wilson, M. S., Overall, N. C., Lee, C. H. J., Milojev, P., Bulbulia, J., Osborne, D., Milfont, T. L., Houkamau, C. A., Duck, I. M., Vickers-Jones, R., \& Barlow, F. K. (2020). Effects of the COVID-19 pandemic and nationwide lockdown on trust, attitudes toward government, and well-being. American Psychologist, 75(5), 618-630. https://doi.org/10.1037/amp0000662

Simonton, D. K. (2000). Creativity: Cognitive, personal, developmental, and social aspects. 
American Psychologist, 55(1), 151-158. https://doi.org/10.1037/0003-066X.55.1.151

Simonton, D. K. (2004). Creativity in science: Chance, logic, genius, and zeitgeist (1st ed.). Cambridge University Press. https://doi.org/10.1017/CBO9781139165358

Sloan, W. W., \& Solano, C. H. (1984). The conversational styles of lonely males with strangers and roommates. Personality and Social Psychology Bulletin, 10(2), 293-301. https://doi.org/10.1177/0146167284102016

Spielberger, C. D. (1983). Manual for the State-Trait Anxiety Inventory STAI (Form Y). Consulting Psychologists Press.

Storme, M., Tavani, J.-L., \& Myszkowski, N. (2016). Psychometric properties of the French Ten-Item Personality Inventory (TIPI). Journal of Individual Differences, 37(2), 81-87. https://doi.org/10.1027/1614-0001/a000204

Taylor, M. R., Agho, K. E., Stevens, G. J., \& Raphael, B. (2008). Factors influencing psychological distress during a disease epidemic: Data from Australia's first outbreak of equine influenza. BMC Public Health, 8(1), 347. https://doi.org/10.1186/1471-2458-8347

The Jamovi project (1.1.9). (2020). [Computer software]. https://www.jamovi.org

Tick, E. (1988). Creativity and loneliness. The Psychotherapy Patient, 4(1), 131-137. https://doi.org/10.1300/J358v04n01_14

Twenge, J. M., Baumeister, R. F., DeWall, C. N., Ciarocco, N. J., \& Bartels, J. M. (2007). Social exclusion decreases prosocial behavior. Journal of Personality and Social Psychology, 92(1), 56-66. https://doi.org/10.1037/0022-3514.92.1.56

Webb, M. E., Little, D. R., \& Cropper, S. J. (2016). Insight is not in the problem: Investigating insight in problem solving across task types. Frontiers in Psychology, 7. https://doi.org/10.3389/fpsyg.2016.01424

Williams, W. C., Morelli, S. A., Ong, D. C., \& Zaki, J. (2018). Interpersonal emotion 
regulation: Implications for affiliation, perceived support, relationships, and well-being. Journal of Personality and Social Psychology, 115(2), 224-254.

https://doi.org/10.1037/pspi0000132

Winnicott, D. W. (1958). The capacity to be alone. The International Journal of Psychoanalysis, 39, 416-420.

World Health Organization. (2020). Mental Health and Psychosocial Considerations during the COVID-19 Outbreak. https://www.who.int/publications-detail-redirect/WHO-2019nCoV-MentalHealth-2020.1 